\title{
A Ternary Catalytic System for the Room Temperature Suzuki-Miyaura Reaction in Water
}

\author{
Aires da Conceição Silva, ${ }^{1}$ Jaqueline Dias Senra, ${ }^{2}$ \\ Andréa Luzia Ferreira de Souza, ${ }^{3}$ and Luiz Fernando Brum Malta ${ }^{1}$ \\ ${ }^{1}$ Instituto de Química, Universidade Federal do Rio de Janeiro, CT Bloco A Lab 641, 21941-909 Rio de Janeiro, RJ, Brazil \\ ${ }^{2}$ Núcleo de Pesquisas de Produtos Naturais, Universidade Federal do Rio de Janeiro, CCS Bloco H, 21941-614 Rio de Janeiro, RJ, Brazil \\ ${ }^{3}$ Instituto de Química, Universidade Federal do Rio de Janeiro, 27930-560 Macaé, RJ, Brazil
}

Correspondence should be addressed to Aires da Conceição Silva; airesquimico@yahoo.com.br

Received 24 August 2013; Accepted 19 September 2013

Academic Editors: R. A. Fallahpour and P. Lorenzo-Luis

Copyright (c) 2013 Aires da Conceição Silva et al. This is an open access article distributed under the Creative Commons Attribution License, which permits unrestricted use, distribution, and reproduction in any medium, provided the original work is properly cited.

The formation of $\operatorname{Pd}(0)$ in the absence of any classical reducing agent in a medium containing $\mathrm{Mg}^{2+} / \mathrm{Al}^{3+}$ layered double hydroxide (LDH) and $\mathrm{N}, \mathrm{N}$-dimethylformamide was evidenced. XRD analysis showed the presence of crystalline phases of palladium in the $\mathrm{Pd} / \mathrm{LDH}$ composite. Suzuki-Miyaura reactions in aqueous medium were carried out at room temperature, and good yields were obtained with bromoarenes and iodoarenes using the ternary system LDH-Pd-CD (cyclodextrin) as catalyst.

\section{Introduction}

Suzuki-Miyaura reaction is one of the most useful palladiumcatalyzed carbon-carbon bond-forming coupling reactions which involve organic electrophiles and organoboron compounds [1-3]. In general, the easy availability of the starting materials (organic halides and boronic acids), high reactivity under mild reaction conditions, the tolerance of a wide range of functionalities, the formation of nontoxic products, the small amount of catalyst used in the reaction, and the possibility of using water as a solvent or cosolvent contribute to their increasing interest [4]. Focus on sustainable development has directed numerous environmental planning of new synthetic methodologies [5]. In this perspective, catalytic processes that minimize or avoid the use of toxic agents are highly desirable. In recent years, the use of soluble supramolecular receptors such as cyclodextrins, has excelled in the most efficient approaches in catalysis taking into account the focus on environmental issues [6].

Cyclodextrins (CDs), cyclic oligosaccharides obtained from the enzymatic degradation of starch, have been applied in several important synthetic transformations [7]. Structurally, they are composed of residues of D-glucopyranose attached to $\alpha$-1,4-linkages. Due to their hydrophobic cavity, a large number of organic compounds can form inclusion complexes of host-guest type in aqueous medium, which causes significant increase of solubility for guest molecules. CDs have been used in catalysis $[7,8]$, in systems of controlled release of drugs $[9,10]$, and in selective removal of organic substrates in wastewater contaminated [11]. CDs can also act as reducing agents and stabilizers of metal nanoparticles $[12,13]$.

Layered double hydroxides (LDHs), hydrotalcite-like compounds, are anionic clays since they present in their interlayer domains anionic species [14]. LDHs can be represented by the general formula $\left[\mathrm{M}_{1-x}{ }^{\mathrm{II}} \mathrm{M}_{x}{ }^{\mathrm{III}}(\mathrm{OH})_{2}\right]^{x+}\left[\mathrm{A}_{x / n}{ }^{n-}\right.$. $\left.\mathrm{mH}_{2} \mathrm{O}\right]^{x-}$, where $\mathrm{M}^{\mathrm{II}}$ and $\mathrm{M}^{\mathrm{III}}$ are divalent and trivalent cations, respectively; the value of $x$ is equal to the molar ratio of $\mathrm{M}^{\mathrm{III}} /\left(\mathrm{M}^{\mathrm{II}}+\mathrm{M}^{\mathrm{III}}\right)$, and $\mathrm{A}$ is the interlayer anion of valence $n$ [15]. The structure of LDHs is based on the positively charged brucite-like sheets, and the positive charges are balanced by anions intercalated in the interlayer regions [16]. LDHs have many applications in heterogeneous catalysis as catalysts or catalyst precursors [17-20].

We believe that the association among cyclodextrins, LDHs, and palladium could exert an outstanding performance towards the Suzuki reaction. Many reactants for this 
reaction are not soluble in water, and this can be remediated by using cyclodextrins and their phase transfer property. Additionally, excellent performances have been reported for the LDH-palladium composite in $\mathrm{C}-\mathrm{C}$ cross-coupling reactions $[18,20]$. Therefore, our work shed light on the influence of the ternary system LDH-Pd-CD on the Suzuki reaction under mild conditions applying aqueous medium.

\section{Experimental}

2.1. Materials. All chemicals were of reagent grade or analytical grade when available and were used without further purification. All aqueous solutions were prepared with MilliQ water.

2.2. Synthesis of $\mathrm{LDH}$. The $\mathrm{Mg} / \mathrm{Al}$ layered double hydroxide was obtained using a solution containing $0.006 \mathrm{~mol}$ of $\mathrm{Mg}\left(\mathrm{NO}_{3}\right)_{2} \cdot 6 \mathrm{H}_{2} \mathrm{O}$ (Vetec, $99 \%$ ) and $0.003 \mathrm{~mol}$ of $\mathrm{Al}\left(\mathrm{NO}_{3}\right)_{3}$. $9 \mathrm{H}_{2} \mathrm{O}$ (Vetec, 99\%) (Mg(II)/Al(III) = 2) in $100 \mathrm{~mL}$ of Milli$\mathrm{Q}$ water. Under vigorous stirring, $\mathrm{LDH}$ was prepared by coprecipitation at $\mathrm{pH}=10$ with a $1.0 \mathrm{~mol} \cdot \mathrm{L}^{-1}$ solution of $\mathrm{NaOH}$ (Vetec, 99\%) at room temperature. The suspension thus obtained was filtered, washed with Milli-Q water, and dried over a stove. The LDH was obtained as a white solid.

\subsection{Synthesis of $\mathrm{Pd} / \mathrm{LDH}$ Composite. $\mathrm{Pd} / \mathrm{LDH}$ composite was} prepared by mixing $0.4 \mathrm{~g} \mathrm{LDH}$ with a $0.025 \mathrm{~mol} \cdot \mathrm{L}^{-1} \mathrm{Na}_{2} \mathrm{PdCl}_{4}$ (Aldrich, 98\%) solution in N,N-dimethylformamide (Aldrich, 99.8\%) (Pd:LDH; $1: 2$ ) at $80^{\circ} \mathrm{C}$ for $24 \mathrm{~h}$. Initially, the palladium solution was yellow; some minutes after $\mathrm{LDH}$ addition to the system, the mixture started to darken, and after about 1 hour of reaction, a black colored precipitate appeared. After 24 hours of reaction, the entire solution became dark. The black solid obtained was filtered, washed with portions of $N, N$-dimethylformamide (DMF), and dried in a properly stove.

2.4. General Procedure for Suzuki Reaction. In a $25 \mathrm{~mL}$ reaction flask the aryl halide (1.0 equivalent), 1.2 equivalents of phenylboronic acid (Aldrich, 95\%), 2.0 equivalents of $\mathrm{K}_{2} \mathrm{CO}_{3}$ (Aldrich, 99.9\%), the palladium catalyst, and $5 \mathrm{~mL}$ of the solvent were added at room temperature. After the end of reaction, the reaction mixture was extracted with $20 \mathrm{~mL}$ of diethyl ether (Vetec, 99.5\%). The organic phase was then filtered on Celite, washed with water, and dried under anhydrous $\mathrm{Na}_{2} \mathrm{SO}_{4}$ (Aldrich, 99\%). The solution was filtered and the solvent was evaporated. The product thus obtained was characterized by GC-MS and ${ }^{1} \mathrm{H}-\mathrm{NMR}$.

2.5. Materials Characterization. Powder X-ray diffraction (XRD) patterns were recorded on a Rigaku Ultima IV diffractometer using $\mathrm{Cu} \mathrm{K} \alpha$ radiation. Scans were performed over $2 \theta$ range from $5^{\circ}$ to $80^{\circ}$, using a resolution of $0.05^{\circ}$ and count time of $1 \mathrm{~s}$ at each point.

Fourier-transform infrared (FTIR) spectra were recorded on a Nicolet Magna-IR 760 spectrophotometer with resolution of $4 \mathrm{~cm}^{-1}$ and a number of 16 scans using wavenumber

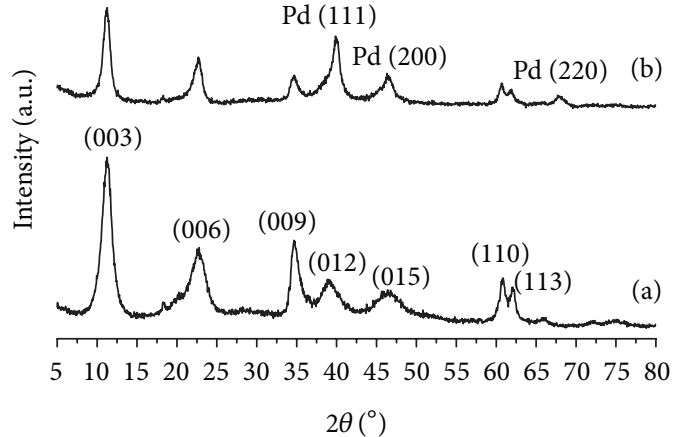

FIGURE 1: XRD patterns of (a) LDH and (b) Pd/LDH composite.

range from 400 to $4000 \mathrm{~cm}^{-1}$. Samples were prepared by mixing the powdered solids with $\mathrm{KBr}$.

$\mathrm{X}$-ray fluorescence (XRF) analysis was performed on a Philips PW 2400 sequential wavelength X-ray spectrometer.

Scanning electron microscopy (SEM) and energydisperse X-ray spectroscopy were performed on a JEOL JSM 6460-LV microscope operating among $10-20 \mathrm{kV}$ and equipped with an energy-disperse $\mathrm{X}$-ray spectrometer.

BET surface areas, pore diameters, and pore volumes were calculated from nitrogen adsorption-desorption isotherms that were obtained at 77.3 K using a Quantachrome NovaWin instrument. Samples were pretreated under vacuum at $453 \mathrm{~K}$ for $5 \mathrm{~h}$ prior to use. Specific surface areas were calculated by the BET method [21], and pore distribution was established by the BJH method [22].

The analysis of gas chromatography-mass spectrometry (GC-MS) was performed on a chromatograph model GCMSQP2010 Plus with a RTX-5MS column (crossband, with the stationary phase of 5\% diphenyl and 95\% dimethyl polysiloxane) about $30 \mathrm{~m} \times 0.25 \mathrm{~mm} \times 0.25 \mu \mathrm{m}$ thick. The carrier gas used was $\mathrm{He}(100.0 \mathrm{kPa})$ at a flow rate of $1.33 \mathrm{~mL} / \mathrm{min}$. The GC interface with a mass selective detector was maintained at $240^{\circ} \mathrm{C}$. The program used in the analysis was as follows: injector temperature $=240^{\circ} \mathrm{C}$, detector temperature $=260^{\circ} \mathrm{C}$, column temperature $=100^{\circ} \mathrm{C}-240^{\circ} \mathrm{C}$, the rate of change of column temperature $=10^{\circ} \mathrm{C} / \mathrm{min}$, and injection volume $=$ $0.5 \mu \mathrm{L}$.

\section{Results and Discussion}

3.1. Powder X-Ray Diffraction. Figure 1 shows the XRD patterns of $\mathrm{LDH}$ (a) and $\mathrm{Pd} / \mathrm{LDH}$ composite (b). The $\mathrm{LDH}$ pattern (Figure 1(a)) is typical of a hydrotalcite-like layered material, having been indexed according to the American Mineralogist card no. 0014738.

The XRD pattern of $\mathrm{Pd} / \mathrm{LDH}$ composite (Figure 1(b)) showed three additional peaks (Figure $1(\mathrm{a})$ ) at $2 \theta=40.15^{\circ}$, $46.7^{\circ}$, and $68.15^{\circ}$. Past works in the literature have reported some modifications in the $\mathrm{LDH}$ diffraction pattern supposedly due to the $\mathrm{PdCl}_{4}{ }^{2-}$ intercalation [18]. In the present work, we searched for the source of the changes observed in the XRD pattern of $\mathrm{Pd} / \mathrm{LDH}$ in face of that of $\mathrm{LDH}$. Based on Crystmet card \#AL3277 we identified these additional 


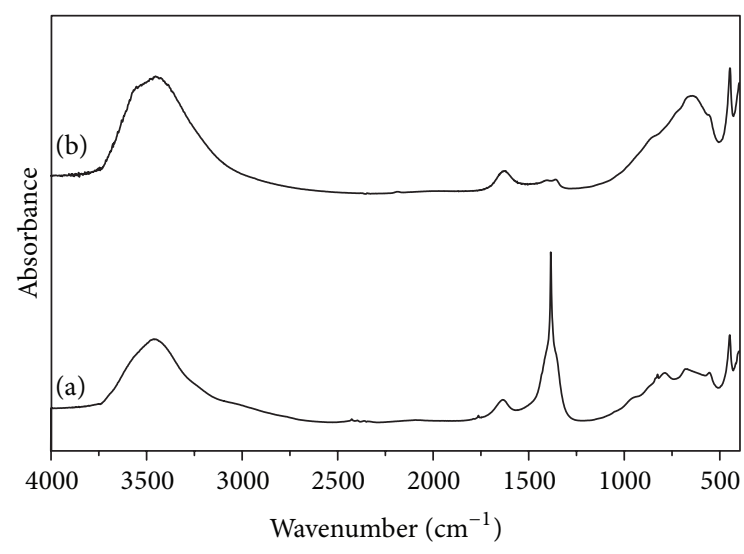

Figure 2: FTIR spectra for (a) LDH and (b) Pd/LDH composite.

TABLE 1: CHN elemental analysis of LDH and Pd/LDH composite.

\begin{tabular}{lccc}
\hline Sample & $\mathrm{C}(\%)$ & $\mathrm{H}(\%)$ & $\mathrm{N}(\%)$ \\
\hline $\mathrm{LDH}$ & 1.25 & 3.73 & 3.56 \\
$\mathrm{Pd} / \mathrm{LDH}$ composite & 1.29 & 3.71 & 0.21 \\
\hline
\end{tabular}

reflections as corresponding to the three planes (111), (200), and (220) of elemental palladium phase that somehow was formed in the material $[23,24]$.

3.2. Fourier-Transform Infrared Spectroscopy. Figure 2 shows the FTIR spectra for LDH and for Pd/LDH composite in the regions between 400 and $4000 \mathrm{~cm}^{-1}$. Both of them exhibit a broad band at $3500 \mathrm{~cm}^{-1}$ that can be assigned to $\mathrm{O}-\mathrm{H}$ stretching, a band at $1630 \mathrm{~cm}^{-1}$ that is typical of the angular deformation vibration of the water molecule, and a band at $450 \mathrm{~cm}^{-1}$ that can be assigned to the $\mathrm{Al}-\mathrm{OH}$ vibrations. Concerning the strong band centered at $1384 \mathrm{~cm}^{-1}$ for LDH it can be assigned as the asymmetric stretching of nitrate $\left(\mathrm{NO}_{3}{ }^{-}\right)$. Since this signal almost disappears in the spectrum of $\mathrm{Pd} / \mathrm{LDH}$ composite (Figure 2(b)), it may be inferred that the ion-exchange process occurred, corroborating the $\mathrm{CHN}$ elemental analysis (Table 1). This analysis indicated a decrease in the amount of nitrogen (from $\mathrm{NO}_{3}{ }^{-}$) for $\mathrm{Pd} / \mathrm{LDH}$ in face of LDH. Another important feature to be discussed in the $\mathrm{Pd} / \mathrm{LDH}$ composite spectrum is the increase of intensity for the $\mathrm{CO}_{3}{ }^{2-}$ in-plane bending mode at $642 \mathrm{~cm}^{-1}$ which according to the literature [25] is correlated with the intercalation process of $\mathrm{PdCl}_{4}{ }^{2-}$ in $\mathrm{LDH}$.

\subsection{Scanning Electron Microcopy and X-Ray Energy Dispersive} Spectroscopy. As part of the morphological analysis, the scanning electron microscopy images from $\mathrm{LDH}$ and $\mathrm{Pd} / \mathrm{LDH}$ composite employing backscattered electrons signals are shown in Figure 3. The left image in Figure 3 evidences that $\mathrm{LDH}$ presents large and heterogeneously sized agglomerates while the right image shows that $\mathrm{Pd} / \mathrm{LDH}$ composite is more dispersed and homogeneous, with smaller particles.

The images of emitted X-rays (Figure 4) for the Pd/LDH composite obtained via X-ray energy dispersive spectroscopy
TABLE 2: Textural properties of LDH and Pd/LDH composite.

\begin{tabular}{lccc}
\hline Sample & $S_{\text {BET }}\left(\mathrm{m}^{2} / \mathrm{g}\right)^{\mathrm{a}}$ & $d_{p}(\mathrm{~nm})^{\mathrm{b}}$ & $V_{p}\left(\mathrm{~cm}^{3} / \mathrm{g}\right)^{\mathrm{c}}$ \\
\hline LDH & 6.099 & 2.161 & 0.0169 \\
Pd/LDH composite & 7.834 & 1.736 & 0.0176 \\
\hline${ }^{\mathrm{a}}$ Specific surface area. ${ }^{\mathrm{b}}$ Pore diameter. & ${ }^{\mathrm{c}}$ Pore volume.
\end{tabular}

show homogeneous distribution of palladium (in red) and chlorine (in blue) throughout the sample. This observation supports that there is no second phase containing palladium segregated from the matrix for this composite, which permits to infer that the metal was inserted in the interlayer space.

The analysis by X-ray fluorescence allowed quantitatively establishing the percentage that each element has in the Pd/LDH composite: Pd: 1.06\%; Mg: 20.13\%; Al: 11.85\%.

3.4. Textural Properties. Table 2 lists the specific surface areas, average pore diameters, and pore volumes of $\mathrm{LDH}$ and $\mathrm{Pd} / \mathrm{LDH}$ composite. $\mathrm{Pd} / \mathrm{LDH}$ composite has greater specific surface area than LDH due to the empty spaces generated in the interlayer region that arises from the stoichiometry of ionexchange process, two $\mathrm{NO}_{3}{ }^{-}$by one $\mathrm{PdCl}_{4}{ }^{2-}$.

With all this in mind it is evident that in a first moment the ion-exchange process occurs between $\mathrm{NO}_{3}{ }^{-}$and $\mathrm{PdCl}_{4}{ }^{2-}$ species followed by a second event in which $\mathrm{Pd}(\mathrm{II})$ is reduced to $\operatorname{Pd}(0)$. Concerning the latter event, we are not aware of any means by which LDH matrix could exert the metallic reduction process. However it is important to say that the ion-exchange process was carried out in the presence of $\mathrm{N}, \mathrm{N}$-dimethylformamide. It is common sense that DMF is not stable in the presence of strong acids or bases. Talking about hydroxides, the products of DMF decomposition are formate ion and dimethylamine by alkaline hydrolysis [26]. By the mechanistic proposal presented in Scheme 1 the formation of palladium (0) is explained from the oxidation of dimethylamine to the corresponding iminium ion. We proposed two mechanisms (associative or dissociative pathways) concerning the substitution of chloride ion by dimethylamine. On the last step the reductive elimination aided by $\mathrm{OH}^{-}$species leads to the formation of $\mathrm{Pd}(0)$.

3.5. Suzuki Reactions. Due to the importance of the Suzuki reactions, we proposed a new method for them. Firstly we tested our catalytic system with the model reaction between 4-bromoacetophenone and phenylboronic acid. All the results are summarized in Table 3.

Experiments to obtain the best solvent composition were processed according to the conditions described in Table 3 , entries 1-4. We chose $\mathrm{Na}_{2} \mathrm{PdCl}_{4} 1 \%$ due to the use of its anion as intercalated species in LDH matrices. Since it is our aim to perform reactions in water-based medium, all solvent compositions contain water in a major percentage. Beyond water, isopropyl alcohol was also tested since it can act as a reducing agent of $\mathrm{Pd}(\mathrm{II})$ (unpublished results).

The result from entry 1 , reaction in neat water, shows that the system is hardly reactive in a time of 24 hours at room temperature, with a conversion of $26 \%$. In entries $2-4$ solvent 


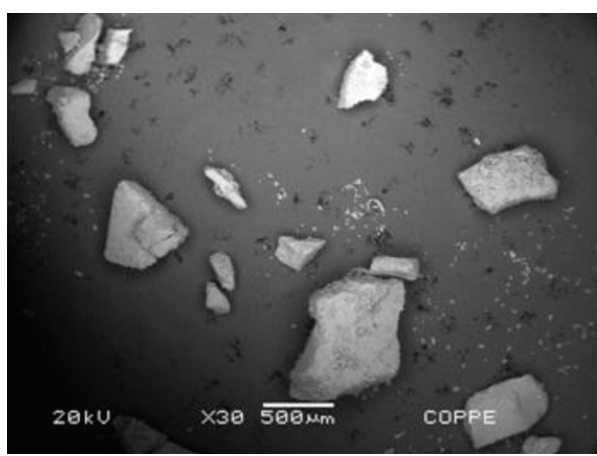

(a)

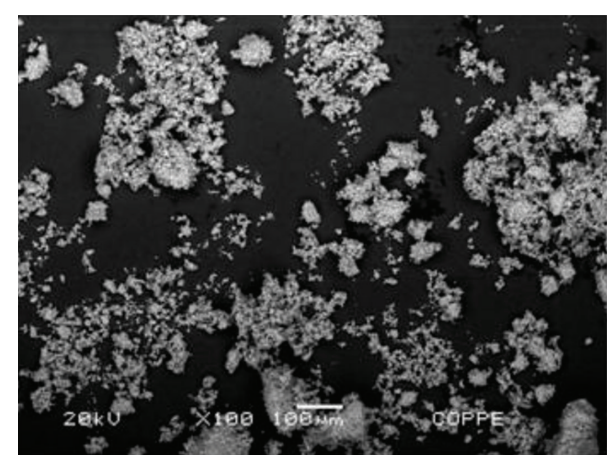

(b)

FIgURE 3: SEM images of LDH ((a) magnification: 30x) and Pd/LDH composite ((b) magnification: 100x).

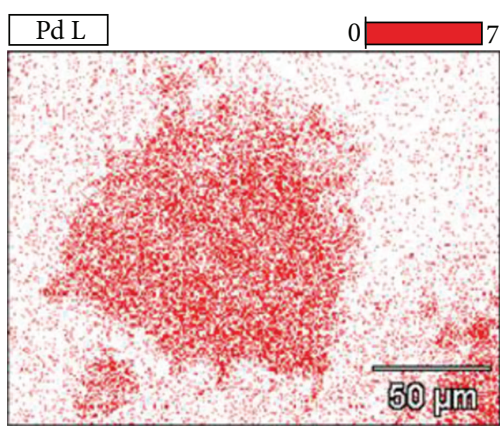

(a)

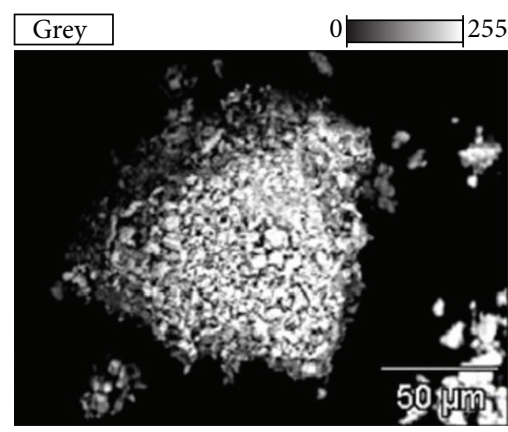

(b)

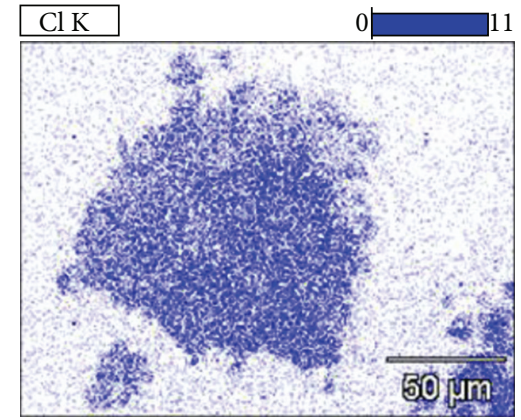

(c)

FIgURE 4: Images of characteristic X-ray emitted by Pd and Cl elements in the Pd/LDH composite.

mixtures between water and isopropyl alcohol were used in different proportions (60-90\% of $\mathrm{H}_{2} \mathrm{O}$ ). In entries 2 and 3 , applying proportions of water: isopropyl alcohol of $60: 40$ and $80: 20$, respectively, complete conversions of the aryl halide into the product were obtained. However the increase of the water content to $90 \%$, entry 4 , led to the conversion dropping to $70 \%$, hence evidencing the influence of isopropyl alcohol in the solvent composition. This result was the starting point to investigate if the addition of cyclodextrin to the reaction medium could improve the conversion.

The native $\beta$-cyclodextrin was used in the experiments 5-7 described in Table 3. Comparing entries 4 and 5 it is clear that the $\mathrm{Pd}: \mathrm{CD}$ ratio of $1: 1$ in the reaction medium practically did not affect the conversion of the starting material. Therefore, a new reaction (entry 6) was carried out applying a $\mathrm{Pd}: \mathrm{CD}$ ratio of $1: 10$. For this run an increase of conversion was observed, probably due to the presence of a greater amount of CD in the medium that can afford a greater dispersion of the reactants, a process that was benefited from the host (CD)-guest (organic molecule) interaction. When a $\mathrm{Pd}$ : CD ratio of $10: 1$ was tested (entry 7 ), a decrease in the conversion of 4-bromoacetophenone occurred, showing that there is an optimum ratio of $\mathrm{Pd}: \beta-\mathrm{CD}(1: 10)$, corresponding to entry 6.

The search for the best cyclodextrin form to perform the aqueous Suzuki reaction took place in the next set of reactions. For the reaction of entry 8 the hydroxypropylated form of $\beta$-CD (HP- $\beta$-CD) was tested and an outstanding conversion of over $99 \%$ was achieved. Aiming to test the effect of an anionic cyclodextrin, the sodium salt of sulfated $\beta-C D$ was used in the reaction of entry 9 and $86 \%$ of the halide was converted into products; however the reaction selectivity was not good, considering that the reacted mixture was $14 \%$ in biphenyl and $72 \%$ in 4 -phenylacetophenone. In all other reactions, homocoupling products were negligible. Therefore, the use of this CD was discarded for future reactions. From this set of experiments, we chose HP- $\beta-C D$ as additive for further reactions.

The excellent result employing HP- $\beta$-CD in the medium of water : isopropyl alcohol $(90: 10)$ encouraged us to perform the same reaction in neat water. These experiments are related in Table 3, entries 10-12. The reaction in entry 10, using $1 \mathrm{~mol} \%$ of the catalyst and a $\mathrm{Pd}: \mathrm{HP}-\beta-\mathrm{CD}$ ration of $1: 10$, gave conversion of over than $99 \%$ evidencing that isopropyl alcohol is not necessary to obtain a high product yield. With this result in mind, the following experiments took place in an attempt to reduce the amount of the catalyst in the reaction medium. Entry 11 shows a reaction where the amount of palladium was reduced by half $(0.5 \%)$, but the conversion of the aryl halide was also significantly reduced. In an attempt to improve this result the reaction of entry 12 was performed using the same catalyst amount but applying a Pd:HP- $\beta-\mathrm{CD}$ ratio of $1: 20$, which afforded an excellent conversion of over than $99 \%$.

The time duration of the Suzuki reaction was screened in order to determine whether applying 24 hours for this 


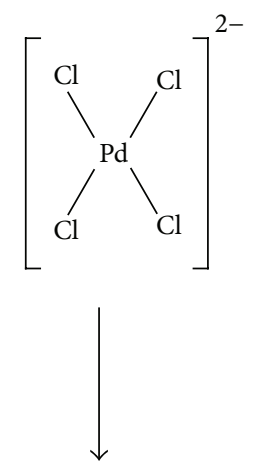<smiles></smiles><smiles>C[Te](Cl)(Cl)Cl</smiles><smiles>CCN(C)[Te](Cl)(Cl)Cl</smiles><smiles>CCC1CCCCC1C=[NH+]C</smiles>

$\mathrm{Pd}(0)+\mathrm{H}_{2} \mathrm{O}+3 \mathrm{Cl}^{-}$
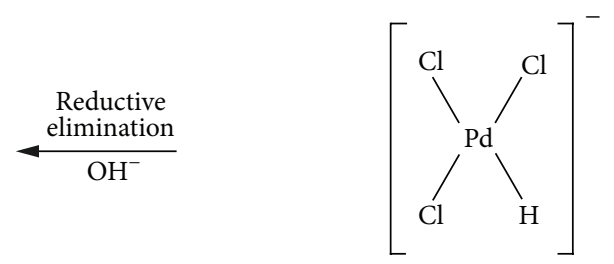

Scheme 1: Mechanistic proposal for the dimethylamine-mediated reduction of $\mathrm{Pd}(\mathrm{II})$ in the interlayer space.

reaction is really necessary. The experiments are related in Table 3, entries 13-17. These experiments proved that the Suzuki reaction occurred with a conversion of over than $99 \%$ after a period of only 8 hours (entry 17) at room temperature using a $1: 20$ ratio of $\mathrm{Pd}: \mathrm{HP}-\beta-\mathrm{CD}$ and $0.5 \%$ of homogeneous catalyst.

In order to continuously improve our system and benefit from the advantages of heterogeneous catalysis, the $\mathrm{Pd} / \mathrm{LDH}$ composite was used as the catalyst. The reaction in entry 18 shows that the heterogeneous catalyst converts over than $99 \%$ of the starting material into product. In entry 19 , the reaction was carried out applying the $\mathrm{Pd} / \mathrm{LDH}$ composite but in the absence of CD: the aryl halide conversion decreased to $93 \%$. This result evidences that there is a synergism between the heterogeneous catalyst and the cyclodextrin. A third reaction (entry 20) was performed without the catalyst (palladium) but with the LDH matrix, and no conversion of the aryl halide into products has occurred.

The reaction of entry 21 was an attempt to reduce the amount of heterogeneous catalyst used in the Suzuki reaction. Reducing it to $0.1 \%$ still permitted a conversion of the starting material greater than 99\%; however further decrease of Pd amount to $0.01 \%$ led to a conversion of only $30 \%$. Therefore the amount of $\mathrm{Pd}$ in the reaction was fixed at $0.1 \%$. The run of entry 23 was an attempt to reduce the reaction time (3 hours) with the same amount of catalyst, but the conversion has also decreased (60\%). Thus, the ideal condition found for the Suzuki reaction in aqueous medium was the one that has employed $0.1 \%$ of $\mathrm{Pd} / \mathrm{LDH}$ composite at room temperature during $8 \mathrm{~h}$ with a Pd:HP- $\beta$-CD ratio of $1: 20$ (entry 21 ).

In order to verify the effectiveness of the ternary system LDH-Pd-CD, another substrate (iodobenzene) was used in the reaction, entries $24-26$ of Table 3 . The entry 24 corresponds to the reaction via homogeneous catalysis $\left(\mathrm{Na}_{2} \mathrm{PdCl}_{4}\right.$ $0.1 \%$ ) and shows a conversion of only $45 \%$ in the presence of HP- $\beta$-CD. The employment of LDH-Pd, with no CD in the reaction medium, improved the conversion to $91 \%$ (entry 26). However, the completion of the reaction was almost achieved when the ternary system LDH-Pd-CD was tested showing a conversion greater than 99\% (entry 25). Figure 5 represents entries 24-26.

The capacity of recycling the heterogeneous catalyst was investigated, and good yields were obtained up to two runs (1st run: $88 \%$, 2nd run: $71 \%$, and 3rd run: $55 \%$ ). 
TABLE 3: Screening of the best condition for the Suzuki reaction between 4-bromoacetophenone and phenylboronic acid.

\begin{tabular}{|c|c|c|c|c|c|c|}
\hline Entry & Solvent & Catalyst & $\mathrm{Pd}: \mathrm{CD}$ & Cyclodextrin & Time (h) & Conversion $^{\mathrm{a}}(\%)$ \\
\hline 1 & $\mathrm{H}_{2} \mathrm{O}$ & $\mathrm{Na}_{2} \mathrm{PdCl}_{4} 1 \%$ & - & - & 24 & 26 \\
\hline 2 & $\mathrm{H}_{2} \mathrm{O}$ : isopropyl alcohol (60\%:40\%) & $\mathrm{Na}_{2} \mathrm{PdCl}_{4} 1 \%$ & - & - & 24 & $>99$ \\
\hline 3 & $\mathrm{H}_{2} \mathrm{O}$ : isopropyl alcohol ( $\left.80 \%: 20 \%\right)$ & $\mathrm{Na}_{2} \mathrm{PdCl}_{4} 1 \%$ & - & - & 24 & $>99$ \\
\hline 4 & $\mathrm{H}_{2} \mathrm{O}$ : isopropyl alcohol (90\%: $\left.10 \%\right)$ & $\mathrm{Na}_{2} \mathrm{PdCl}_{4} 1 \%$ & - & - & 24 & 70 \\
\hline 5 & $\mathrm{H}_{2} \mathrm{O}$ : isopropyl alcohol (90\%:10\%) & $\mathrm{Na}_{2} \mathrm{PdCl}_{4} 1 \%$ & $1: 1$ & $\beta-\mathrm{CD}$ & 24 & 68 \\
\hline 6 & $\mathrm{H}_{2} \mathrm{O}$ : isopropyl alcohol (90\%: $\left.10 \%\right)$ & $\mathrm{Na}_{2} \mathrm{PdCl}_{4} 1 \%$ & $1: 10$ & $\beta-\mathrm{CD}$ & 24 & 86 \\
\hline 7 & $\mathrm{H}_{2} \mathrm{O}$ : isopropyl alcohol (90\%:10\%) & $\mathrm{Na}_{2} \mathrm{PdCl}_{4} 1 \%$ & $10: 1$ & $\beta-\mathrm{CD}$ & 24 & 59 \\
\hline 8 & $\mathrm{H}_{2} \mathrm{O}$ : isopropyl alcohol (90\%: $\left.10 \%\right)$ & $\mathrm{Na}_{2} \mathrm{PdCl}_{4} 1 \%$ & $1: 10$ & $\mathrm{HP}-\beta-\mathrm{CD}$ & 24 & $>99$ \\
\hline 9 & $\mathrm{H}_{2} \mathrm{O}$ : isopropyl alcohol (90\%:10\%) & $\mathrm{Na}_{2} \mathrm{PdCl}_{4} 1 \%$ & $1: 10$ & $\beta$-CD, sulfated sodium salt & 24 & 86 \\
\hline 10 & $\mathrm{H}_{2} \mathrm{O}$ & $\mathrm{Na}_{2} \mathrm{PdCl}_{4} 1 \%$ & $1: 10$ & $\mathrm{HP}-\beta-\mathrm{CD}$ & 24 & $>99$ \\
\hline 11 & $\mathrm{H}_{2} \mathrm{O}$ & $\mathrm{Na}_{2} \mathrm{PdCl}_{4} 0.5 \%$ & $1: 10$ & $\mathrm{HP}-\beta-\mathrm{CD}$ & 24 & 66 \\
\hline 12 & $\mathrm{H}_{2} \mathrm{O}$ & $\mathrm{Na}_{2} \mathrm{PdCl}_{4} 0.5 \%$ & $1: 20$ & $\mathrm{HP}-\beta-\mathrm{CD}$ & 24 & $>99$ \\
\hline 13 & $\mathrm{H}_{2} \mathrm{O}$ & $\mathrm{Na}_{2} \mathrm{PdCl}_{4} 0.5 \%$ & $1: 20$ & $\mathrm{HP}-\beta-\mathrm{CD}$ & 2 & 57 \\
\hline 14 & $\mathrm{H}_{2} \mathrm{O}$ & $\mathrm{Na}_{2} \mathrm{PdCl}_{4} 0.5 \%$ & $1: 20$ & $\mathrm{HP}-\beta-\mathrm{CD}$ & 4 & 58 \\
\hline 15 & $\mathrm{H}_{2} \mathrm{O}$ & $\mathrm{Na}_{2} \mathrm{PdCl}_{4} 0.5 \%$ & $1: 20$ & $\mathrm{HP}-\beta-\mathrm{CD}$ & 6 & 89 \\
\hline 16 & $\mathrm{H}_{2} \mathrm{O}$ & $\mathrm{Na}_{2} \mathrm{PdCl}_{4} 0.5 \%$ & $1: 20$ & $\mathrm{HP}-\beta-\mathrm{CD}$ & 7 & 93 \\
\hline 17 & $\mathrm{H}_{2} \mathrm{O}$ & $\mathrm{Na}_{2} \mathrm{PdCl}_{4}$ 0.5\% & $1: 20$ & $\mathrm{HP}-\beta-\mathrm{CD}$ & 8 & $>99$ \\
\hline 18 & $\mathrm{H}_{2} \mathrm{O}$ & $\mathrm{Pd} / \mathrm{LDH}$ 0.5\% & $1: 20$ & $\mathrm{HP}-\beta-\mathrm{CD}$ & 8 & $>99$ \\
\hline 19 & $\mathrm{H}_{2} \mathrm{O}$ & Pd/LDH 0.5\% & - & - & 8 & 93 \\
\hline 20 & $\mathrm{H}_{2} \mathrm{O}$ & $\mathrm{HDL}$ & - & $\mathrm{HP}-\beta-\mathrm{CD}$ & 8 & - \\
\hline 21 & $\mathrm{H}_{2} \mathrm{O}$ & $\mathrm{Pd} / \mathrm{LDH}$ 0.1\% & $1: 20$ & $\mathrm{HP}-\beta-\mathrm{CD}$ & 8 & $>99$ \\
\hline 22 & $\mathrm{H}_{2} \mathrm{O}$ & $\mathrm{Pd} / \mathrm{LDH}$ 0.01\% & $1: 20$ & $\mathrm{HP}-\beta-\mathrm{CD}$ & 8 & 30 \\
\hline 23 & $\mathrm{H}_{2} \mathrm{O}$ & Pd/LDH 0.1\% & $1: 20$ & $\mathrm{HP}-\beta-\mathrm{CD}$ & 3 & 60 \\
\hline $24^{\mathrm{b}}$ & $\mathrm{H}_{2} \mathrm{O}$ & $\mathrm{Na}_{2} \mathrm{PdCl}_{4} 0.1 \%$ & $1: 20$ & $\mathrm{HP}-\beta-\mathrm{CD}$ & 8 & 45 \\
\hline $25^{\mathrm{b}}$ & $\mathrm{H}_{2} \mathrm{O}$ & $\mathrm{Pd} / \mathrm{LDH} 0.1 \%$ & $1: 20$ & $\mathrm{HP}-\beta-\mathrm{CD}$ & 8 & $>99$ \\
\hline $26^{\mathrm{b}}$ & $\mathrm{H}_{2} \mathrm{O}$ & $\mathrm{Pd} / \mathrm{LDH}$ 0.1\% & - & - & 8 & 91 \\
\hline
\end{tabular}

${ }^{\mathrm{a}}$ Conversion of aryl halide into products measured by GC-MS.

${ }^{b}$ Reaction between iodobenzene and phenylboronic acid.

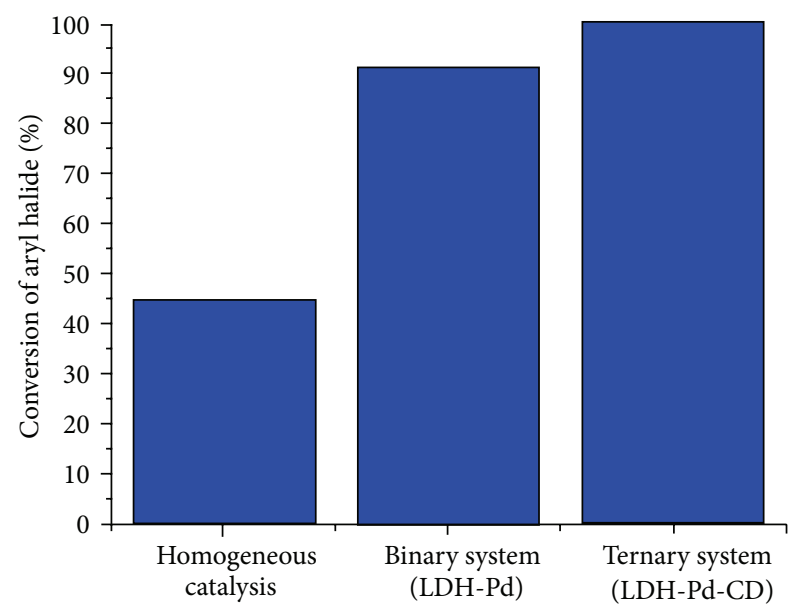

FIGURE 5: Differences among homogeneous catalysis, binary system (LDH-Pd) and ternary system (LDH-Pd-CD) in the reaction of iodobenzene and phenylboronic acid.

To verify the scope of our method employing the ternary system LDH-Pd-CD, other substrates were used (Table 4).

The reaction with 4-bromoacetophenone has provided a good yield of 4-phenylacetophenone due to the presence of an electron-withdrawing group (entry 1). For iodoarene substrates (entries 2-4) good yields were independently found whether electron-withdrawing (entry 3 ) or electron-donating groups (entry 4) are present. The reaction of bromobenzene (entry 5) provides a conversion of $93 \%$ to biphenyl, showing that the conversion is not as good as that of iodobenzene (entry 2). Entries 6 and 7 present the less reactive substrates (chloroarene substrates) affording low yields $(<20 \%)$ even after 24 hours of reaction under reflux. The results of entries 2,5 , and 6 are in conformity with the order of reactivity of chloro-, bromo-, and iodoarenes towards the oxidative addition.

\subsection{Spectral Data}

Biphenyl. White solid. ${ }^{1} \mathrm{H}$ NMR $\left(\mathrm{CDCl}_{3}, 200 \mathrm{MHz}\right) \delta 7.81-7.65$ (4H, d), 7.55-7.42 (4H, dd), 7.37-7.27 (2H, d); GC-MS: $m / z=$ 77,154 .

4-Nitrobiphenyl. Yellow solid. ${ }^{1} \mathrm{H}$ NMR $\left(\mathrm{CDCl}_{3}, 200 \mathrm{MHz}\right) \delta$ $8.30(2 \mathrm{H}, \mathrm{d}), 7.74(2 \mathrm{H}, \mathrm{d}), 7.64(2 \mathrm{H}, \mathrm{d}), 7.52-7.44(3 \mathrm{H}, \mathrm{m})$; GCMS: $m / z=141,152,199$.

4-Phenylacetophenone. Pale yellow solid. ${ }^{1} \mathrm{H}$ NMR $(200 \mathrm{MHz}$, $\left.\mathrm{CDCl}_{3}\right) \delta 8.06-8.02(2 \mathrm{H}, \mathrm{d}), 7.72-7.62(4 \mathrm{H}, \mathrm{m}), 7.52-7.27(3 \mathrm{H}$, m), 2.65 (3H, s); GC-MS: $m / z=76,152,181,196$.

4-Methylbiphenyl. White solid. ${ }^{1} \mathrm{H}$ NMR $\left(200 \mathrm{MHz}, \mathrm{CDCl}_{3}\right)$ $\delta 7.59(2 \mathrm{H}, \mathrm{d}), 7.49(2 \mathrm{H}, \mathrm{d}), 7.40(2 \mathrm{H}, \mathrm{dd}), 7.34(1 \mathrm{H}, \mathrm{d}), 7.28$ (2H, d), $2.46(3 \mathrm{H}, \mathrm{s})$; GC-MS: $m / z=152,168$. 
TABLE 4: Suzuki reactions between different aryl halides and phenylboronic acid using the ternary system (LDH-Pd-CD) at room temperature during 8 hours with $1: 20$ ratio of Pd:HP- $\beta$-CD.

\begin{tabular}{lccc}
\hline Entry & Aryl halide & Product & Yield (\%) \\
\hline 1 & 4-Bromoacetophenone & 4-Phenylacetophenone & $98^{\mathrm{a}}$ \\
2 & Iodobenzene & Biphenyl & $97^{\mathrm{a}}$ \\
3 & 4-Iodonitrobenzene & 4 -Nitrobiphenyl & $98^{\mathrm{a}}$ \\
4 & 4-Iodotoluene & 4 -Methylbiphenyl & $96^{\mathrm{a}}$ \\
5 & Bromobenzene & Biphenyl & $93^{\mathrm{b}}$ \\
6 & Chlorobenzene & Biphenyl & $13^{\mathrm{b}, \mathrm{c}}$ \\
7 & 4-Chloronitrobenzene $^{\mathrm{b}}$ & 4-Nitrobiphenyl & $16^{\mathrm{b}, \mathrm{c}}$ \\
\hline
\end{tabular}

${ }^{\mathrm{a}}$ Isolated yield. ${ }^{\mathrm{b}}$ Measured by GC-MS. ${ }^{\mathrm{c}} 24$ hours under reflux.

\section{Conclusion}

This work has evidenced the presence of $\operatorname{Pd}(0)$ for the $\mathrm{Pd} / \mathrm{LDH}$ composite. It means that $\mathrm{Pd}$ (II) reduction occurred in the presence of layered double hydroxide and $N, N$ dimethylformamide, and to our knowledge it is the first time that such mechanism of reduction is suggested. The same proposal may apply to the formation of gold particles on LDH, recently studied by our group [27]. The ternary system $\mathrm{LDH}-\mathrm{Pd}-\mathrm{CD}$ at room temperature in aqueous medium has proven to be effective as a method for the Suzuki reaction employing iodo- and bromoarenes substrates.

Taking into account the results obtained for the Suzuki reaction, the ternary catalytic system has potential to be successfully employed in other carbon-carbon cross-coupling reactions, as Heck, Sonogashira and Stille reactions.

\section{Acknowledgments}

The authors thank the financial support from CNPq (Process 473754/2010-0), CAPES, and FAPERJ (Process E-26/110.966/ 2009).

\section{References}

[1] N. Miyaura and A. Suzuki, "Palladium-catalyzed cross-coupling reactions of organoboron compounds," Chemical Reviews, vol. 95, no. 7, pp. 2457-2483, 1995.

[2] A. Suzuki, "Recent advances in the cross-coupling reactions of organoboron derivatives with organic electrophiles, 1995-1998," Journal of Organometallic Chemistry, vol. 576, no. 1-2, pp. 147$168,1999$.

[3] S. Liu, Q. Zhou, Z. Jin, H. Jiang, and X. Jiang, "Dodecylsulfate anion embedded layered double hydroxide supported nanopalladium catalyst for the Suzuki reaction," Chinese Journal of Catalysis, vol. 31, no. 5, pp. 557-561, 2010.

[4] F. Alonso, I. P. Beletskaya, and M. Yus, "Non-conventional methodologies for transition-metal catalysed carbon-carbon coupling: a critical overview. Part 2: The Suzuki reaction," Tetrahedron, vol. 64, no. 14, pp. 3047-3101, 2008.

[5] R. A. Sheldon, “The E Factor: fifteen years on," Green Chemistry, vol. 9, no. 12, pp. 1273-1283, 2007.

[6] M. J. Wilkinson, P. W. N. M. Van Leeuwen, and J. N. H. Reek, "New directions in supramolecular transition metal catalysis," Organic \& Biomolecular Chemistry, vol. 3, no. 13, pp. 2371-2383, 2005.
[7] A. R. Hedges, "Industrial applications of cyclodextrins," Chemical Reviews, vol. 98, no. 5, pp. 2035-2044, 1998.

[8] J. D. Senra, L. F. B. Malta, A. L. F. de Souza, M. E. Medeiros, L. C. S. Aguiar, and O. A. C. Antunes, "Phosphine-free Heck reactions in aqueous medium using hydroxypropylated cyclodextrins as supramolecular hosts," Tetrahedron Letters, vol. 48, no. 46, pp. 8153-8156, 2007.

[9] K. Uekama, "Recent aspects of pharmaceutical application of cyclodextrins," Journal of Inclusion Phenomena, vol. 44, no. 1-4, pp. 3-7, 2002.

[10] C. Park, H. Youn, H. Kim et al., "Cyclodextrin-covered gold nanoparticles for targeted delivery of an anti-cancer drug," Journal of Materials Chemistry, vol. 19, no. 16, pp. 2310-2315, 2009.

[11] A. Cassez, A. Ponchel, H. Bricout, S. Fourmentin, D. Landy, and E. Monflier, "Eco-efficient catalytic hydrodechlorination of carbon tetrachloride in aqueous cyclodextrin solutions," Catalysis Letters, vol. 108, no. 3-4, pp. 209-214, 2006.

[12] J. D. Senra, L. F. B. Malta, A. L. F. Souza, L. C. S. Aguiar, and O. A. C. Antunesa, "Palladium on calcium carbonate combined to 2hydroxypropyl- $\alpha / \beta$ - cyclodextrins: A selective catalytic system for aqueous heck coupling and hydroarylation," Advanced Synthesis \& Catalysis, vol. 350, no. 16, pp. 2551-2558, 2008.

[13] J. D. Senra, L. F. B. Malta, M. E. H. M. Da Costa et al., "Hydroxypropyl-a-cyclodextrin-capped palladium nanoparticles: active scaffolds for efficient carbon-carbon bond forming cross-couplings in water," Advanced Synthesis \& Catalysis, vol. 351, no. 14-15, pp. 2411-2422, 2009.

[14] V. Rives and M. A. Ulibarri, "Layered double hydroxides $(\mathrm{LDH})$ intercalated with metal coordination compounds and oxometalates," Coordination Chemistry Reviews, vol. 181, no. 1, pp. 61-120, 1999.

[15] E. M. Sabbar, M. E. de Roy, and F. Leroux, "New Cu and/or Pt complexes intercalated MgAl-hydrotalcite-type anionic clays: synthesis, characterization, thermal behavior and textural properties," Microporous and Mesoporous Materials, vol. 103, no. 1-3, pp. 134-141, 2007.

[16] X. Liang, Y. Zang, Y. Xu et al., "Sorption of metal cations on layered double hydroxides," Colloids and Surfaces A, vol. 433, pp. 122-131, 2013.

[17] Z. P. Xu, J. Zhang, M. O. Adebajo, H. Zhang, and C. Zhou, "Catalytic applications of layered double hydroxides and derivatives," Applied Clay Science, vol. 53, no. 2, pp. 139-150, 2011.

[18] M. Mora, C. Jiménez-Sanchidrián, and J. R. Ruiz, "Heterogeneous Suzuki cross-coupling reactions over palladium/ hydrotalcite catalysts," Journal of Colloid and Interface Science, vol. 302, no. 2, pp. 568-575, 2006. 
[19] D. Francová, N. Tanchoux, C. Gérardin et al., "Hydrogenation of 2-butyne-1,4-diol on supported Pd catalysts obtained from LDH precursors," Microporous and Mesoporous Materials, vol. 99, no. 1-2, pp. 118-125, 2007.

[20] C. Jiménez-Sanchidrián, M. Mora, and J. R. Ruiz, "Suzuki cross-coupling reaction over a palladium-pyridine complex immobilized on hydrotalcite," Catalysis Communications, vol. 7, no. 12, pp. 1025-1028, 2006.

[21] S. Brunauer, P. H. Emmett, and E. Teller, "Adsorption of gases in multimolecular layers," Journal of the American Chemical Society, vol. 60, no. 2, pp. 309-319, 1938.

[22] E. P. Barrett, L. G. Joyner, and P. P. Halenda, "The determination of pore volume and area distributions in porous substances. I. Computations from nitrogen isotherms," Journal of the American Chemical Society, vol. 73, no. 1, pp. 373-380, 1951.

[23] J. Feng, X. Ma, Y. He, D. G. Evans, and D. Li, "Synthesis of hydrotalcite-supported shape-controlled Pd nanoparticles by a precipitation-reduction method," Applied Catalysis A, vol. 413414, pp. 10-20, 2012.

[24] Y. Xiong, J. Chen, B. Wiley, Y. Xia, S. Aloni, and Y. Yin, "Understanding the role of oxidative etching in the polyol synthesis of Pd nanoparticles with uniform shape and size," Journal of the American Chemical Society, vol. 127, no. 20, pp. 7332-7333, 2005.

[25] M. Mora, M. I. Lopez, C. Jiménez-Sanchidrián, and J. R. Ruiz, "Near-infrared spectroscopy of palladium-containing layered double hydroxides used as catalysts," Journal of Physics and Chemistry of Solids, vol. 72, no. 3, pp. 214-219, 2011.

[26] E. Buncel and E. A. Symons, "The inherent instability of dimethylformamide-water systems containing hydroxide ion," Journal of the Chemical Society D, no. 3, pp. 164-165, 1970.

[27] A. C. Silva, A. L. F. Souza, R. A. Simão, and L. F. B. Malta, "A simple approach for the synthesis of gold nanoparticles mediated by layered double hydroxide," Journal of Nanomaterials, vol. 2013, Article ID 357069, 6 pages, 2013. 

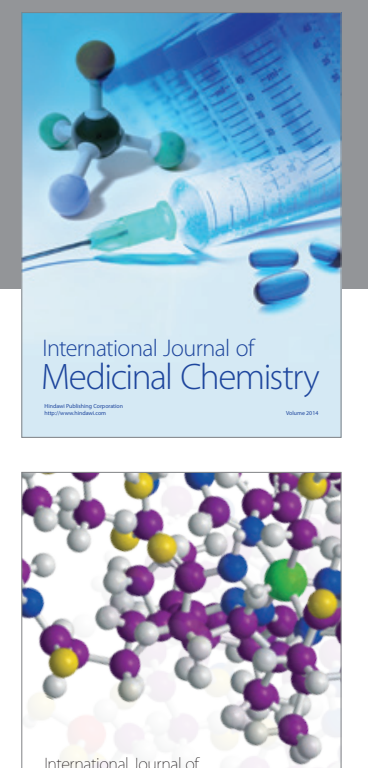

\section{Carbohydrate} Chemistry

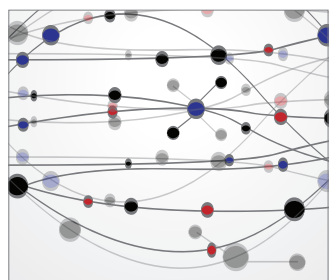

The Scientific World Journal
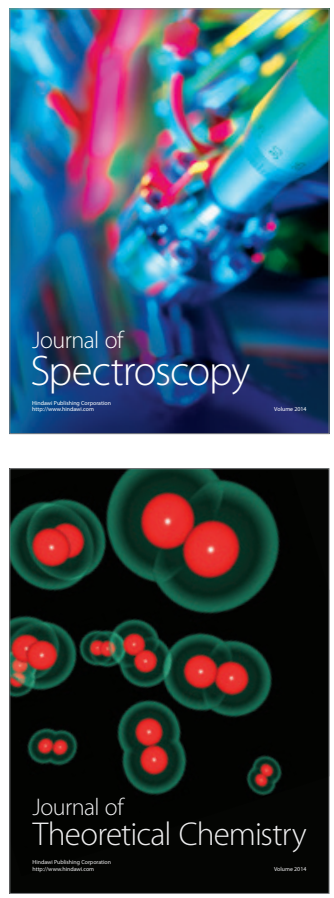
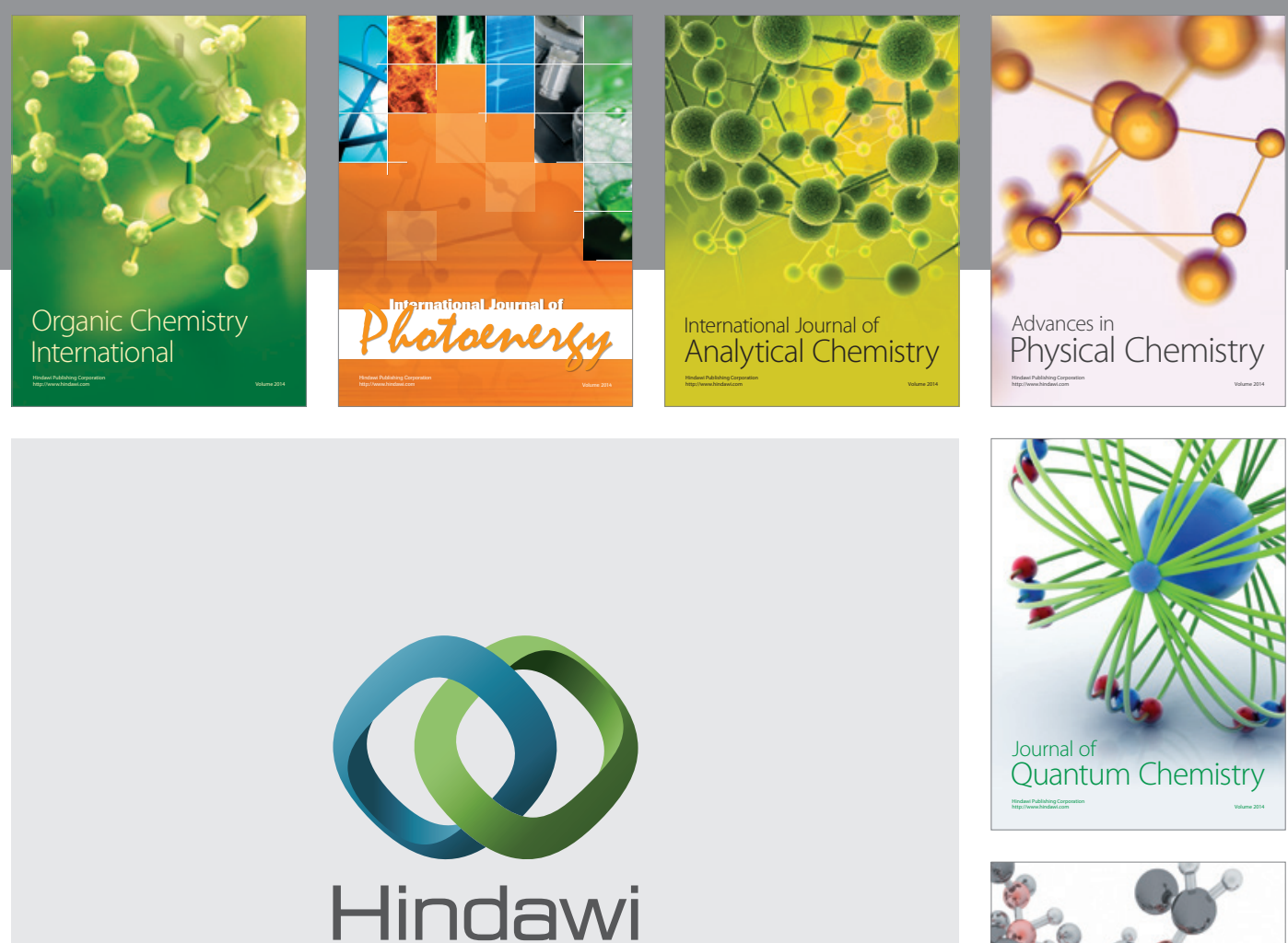

Submit your manuscripts at

http://www.hindawi.com

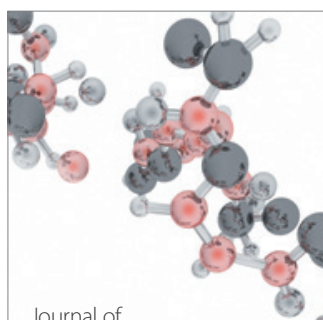

Analytical Methods

in Chemistry

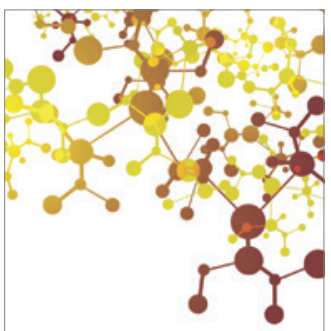

Journal of

Applied Chemistry

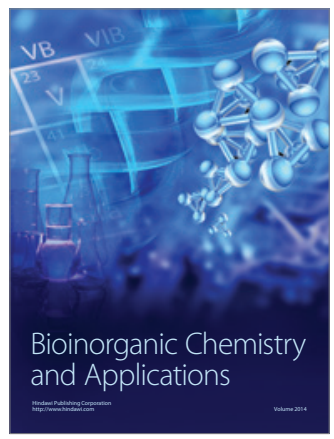

Inorganic Chemistry
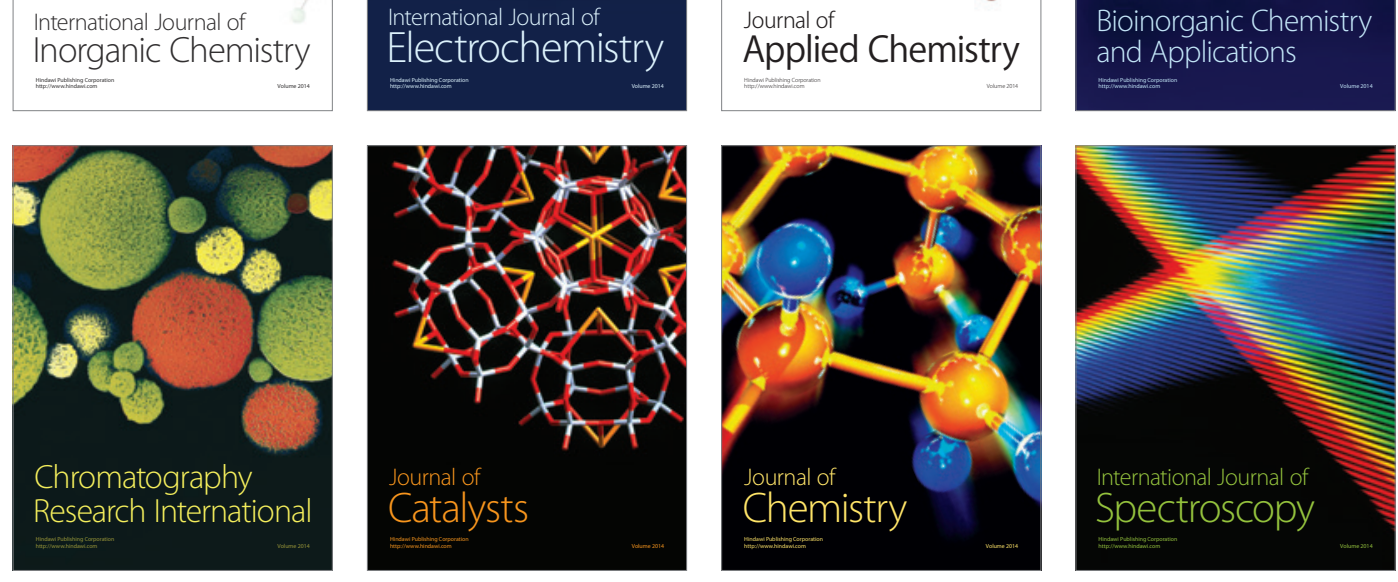